\title{
Comparison Study of Advertising Videos of Tourism City Image- Based on the Content Analysis Method
}

\author{
Zhi-qiang Hou \\ College of tourism, Huaqiao University, Quanzhou 362021, CHINA
}

Received 17 April 2017 • Revised 25 August 2017 • Accepted 25 September 2017

\begin{abstract}
Since the mid-1990s, both domestic and international tourism in China has grown rapidly in many destinations. In particular, city tourism plays an important role as a major destination in regional tourism development. To promote tourism, understanding image and promotion has become the key point in the development of regional tourism economy. Tour cities image advertising videos, the most visual description and most vivid illustration, have been one of the most important means in the images advertising videos of city destinations. Based on the internet, this article takes advertising videos of main tour cities in China as research data, acquires methods of movie reviews, and studies the content and techniques of the photographers. Moreover, this author puts forward suggestions on the images advertising videos of tour cities from the angles of subjects, contents and techniques of shooting.
\end{abstract}

Keywords: tourism city image, tourism advertising videos, content analysis method

\section{INTRODUCTION}

With the development of tourism industry, tourism plays a more and more important role in the progress of main cities in China and has become the new economic growth point, and thus many cities have given the priorities to the tourism development. Meanwhile, with the increasing fierce competition of tourism market, understanding marketing decision process of tourists will be a main task for marketers in city destinations since tourists have many destination options to choose from. One of key selecting factors of destination is the individual's perceived image of a destination (Chon, 1990), which has been concerned in the past decades(Pike, 2002).A complete destination image was reported to include attribute-based images, holistic impressions, and functional, psychological, unique and common characteristics (Echtner and Ritchie, 1993).Hence, the media and communication technology in its many forms has been instrumental in popularizing tourist venues and can have the impact of introducing tourism to these places or boosting tourism numbers. These are facilitated by intermediaries and produced imagination in, for instance, the media, literature, arts, and popular culture (e.g., motion pictures, TV shows, or music) (CohenHattab and Kerber, 2004). For example, the visual rhetoric of advertising was widely used in the marketing of destinations and place branding (Campelo et al., 2011). In China, more and more city destinations use a promotional video/video clip via TV, the Internet and YouTube as a way to improve and create their images in tourists' mind, which are directly related to the success of city tourism promotion efforts. Tourism promotional film is a kind of artistic creation which is based on the combination of the related elements of tourism destination or scenic spot through the sound, light and television technology. Taking the image film- "Hospitable Shandong" as an example, according to data of CCTV cable Furui Company, in 2008, the 71\% of television viewers, about 9.12 million people

(C) Authors. Terms and conditions of Creative Commons Attribution 4.0 International (CC BY 4.0) apply. Correspondence: Zhi-qiang Hou, College of tourism, Huaqiao University, Quanzhou 362021, China. 


\section{Contribution of this paper to the literature}

- Advertising videos of tourism city image play a more and more important role on the individual's perceived image of a destination. So, how to make an efficient video will be a challenge work. In this paper, we want to achieve best image advertising videos of the tour city by finding the basic issues from a lot of videos.

- Advertising videos of tourism city image are made by different production organizations, and some by companies, some by governments. How to judge these videos and make useful suggestion to those producers will be an important work.

- In this paper we not only analysis the diversity of content or the complex of performance techniques of these videos by using content analysis method, but also audience and media must be taken into consideration in the further study.

watched this film; 2.68 million people of them have seen more than 3 times. In 2012, a total of more than 400 films of provinces, cities and scenic spots were broadcast on the CCTV.

The relative researches about tourism advertising videos started from early 1970s, with their stresses on 1) the analysis into the inherent law and their behavior responses from the subjective perception of tourists and potential tourists to tourism destination image; 2) the abstraction of influencing elements of destination image, 3) the researches on the estimation of destination image by using lots of pharmacy mathematical statistics and computer aided technique; 4) the researches on the market positioning strategy, competition strategy of destination image, as well as the basic theoretical exploration based on "human". (Baloglu and McCleary, 1999).

The researches in Chinese developed comparatively lately, from the middle 1990s. They showed interests in the plan and design of tourism images, emphasized the practical theoretical research and follow the rules of pragmatism (Li, 1999). Studies in China mainly focused on the field of practical research on the tourism destination's image planning by way of CIS mode, however, there were $d$ not enough in acquiring quantification study on the basis of experimental data. $\mathrm{Li}(\mathrm{Li}, 1999)$ concluded the general method of image propagating. Huang (Huang, 2002) studied the tourism city image from the angle of advertisement. Cheng (Cheng, 2011) divided the image into visual image, auditory image, olfactory image, taste image and tactile image; while the television image is the integration of the visual and auditory image. This study illustrated the modes of tour destination image promoting from the aspects of promotion organizing and integration. In recent years, domestic researches on tourism destination image showed a trend of quantification and theoretical. Wang (Wang, 2008) put forward the innovative ways of promoting image of tourism destination such as making media focus, arousing public interests and propagating flexible implicit through qualitative and quantitative researches by using SPSS software, questionnaire and interview; Tao et al (Tao et al., 2010) assessed the influencing factors of city tourism image based on the Structural Equation Model (SEM).

Most studies paid attention to tourism media due to the importance of tourism image. Mercille(Mercille, 2005) studied the effects of media expression (including movie, tour guide and magazine) on tour destination image, taking the media effect as the theoretical framework; Meaney and Robb (Meaney and Robb, 2006) discussed the influence of the media of film on the audience and tourism market through the promotion of tourism attractions or site of technology management. The tourism television advertising (TVCs) was viewed as the channel or agent to construct the destination image; the effect of TVCs was related to the recognition of visual elements and the tour destination image (Pan, 2011). In recent years, domestic studies began to concern about the tourism image, including the relative researches on TVCs strategy, tourism destination image and TV media strategy of China's tourism market (Zhou and Fang, 2010; Li and W., 2006).

Content analysis (CA) became one of the main methods in social researches. CA is a research technique of copy and effectively utilization from data to text content. It is a systematic, objective and quantitative analysis of information characteristics (Krippendorf, 1980; Neuendorf, 2002). CA method has been widely used in tourism research, from the analysis of the issue of tourism policy to the analysis of various contents published in the academic journal of tourism. Such as tourism industry code of ethics content investigation and study (Malloy and 
Fennell, 1998; Swain et al., 1999; Padgett and Hall, 2001; Choia et al., 2007; Yan and Zhang, 2010; Mackay et al., 2017). Therefore, the CA method has a wide range of applicability in the field of tourism research.

In order to examine the tourism city image strategy, this study starts from the research of advertising videos of main tourism cities in China, with the wishes to do some beneficial analysis and attempts for the propagating strategies into tour city images. Thus, the goals of our study are to examine the content and expression techniques of ten city tourism image advertising videos through the CA method from the perspective of tourism elements.

\section{RESEARCH METHOD}

\section{Research Framework}

The angle refers to the contact relationship between the subjects and objects of movie reviews. Because of the variety of contact relationship, different angles will have different effects. As a result, it is necessary to choose the angle of movie review.

Movie Reviews point of view can be divided into the following:

1) Viewpoint. Viewpoint, as the cut point of works, can be divided into subjects, objects and multidimensional view. Subject viewpoints are anchor points and inspecting points based on sociology, philosophy, politics and psychology. Object angles are the targeted parts such as plots, style, works and real life, art form, ideology.

2) Perspective. Perspective is the range of object target, including partial perspective, overall perspective and macro perspective. Partial perspective refers to factors as photography, as unexpected factors in the plot and scenery shots in the frame. Overall perspective is something such as style, ideological and artistic tendencies, art ideas, and aesthetics and so on. Macro perspective is the movie phenomenon formed by a series of works, such as general tendency, regular features and the development path of a period or a certain type.

3) Comparison. To compare different movie phenomena in certain relationships, the comparing targets must have comparability. It can be divided into vertical and horizontal comparison. The angle of vertical comparison puts the comparing targets in the historical evolution. While horizontal comparison compares the targets in certain environment.

4) Starting point is to make clear the motives, intentions of reviews. It includes reality, enjoy requirements, personal feeling and meaning of work itself. Taking meaning of work itself as starting points mainly refers to the study into content and form of itself; meaning and value; characteristics and relationship.

\section{Study Design}

There are not many works on researches of propagating strategies about tour cities image by means of analysis advertising videos through film review. Except for some reviews made by professional films commentators, most of the reviews are made by laypeople. Film review is seldom acquired by tourism researchers. As far as film review is concerned, its essence is by way of analyzing the content and technique of expression of video works to analyze and find out its theme, leading function to the public and technique direction so as to explore its law of development and draw out the strategies and methods.

Thus, this article mainly acquires methods of form-analysis-oriented film review, taking mass communication as its subjective viewpoint, works' meaning itself as starting point, choosing holistic style, structure, elements representation and voice as objective viewpoint, compares transversely the content and techniques of expression in the advertising videos of China top ten tour cities. The technical route of this article is as Figure 1. 


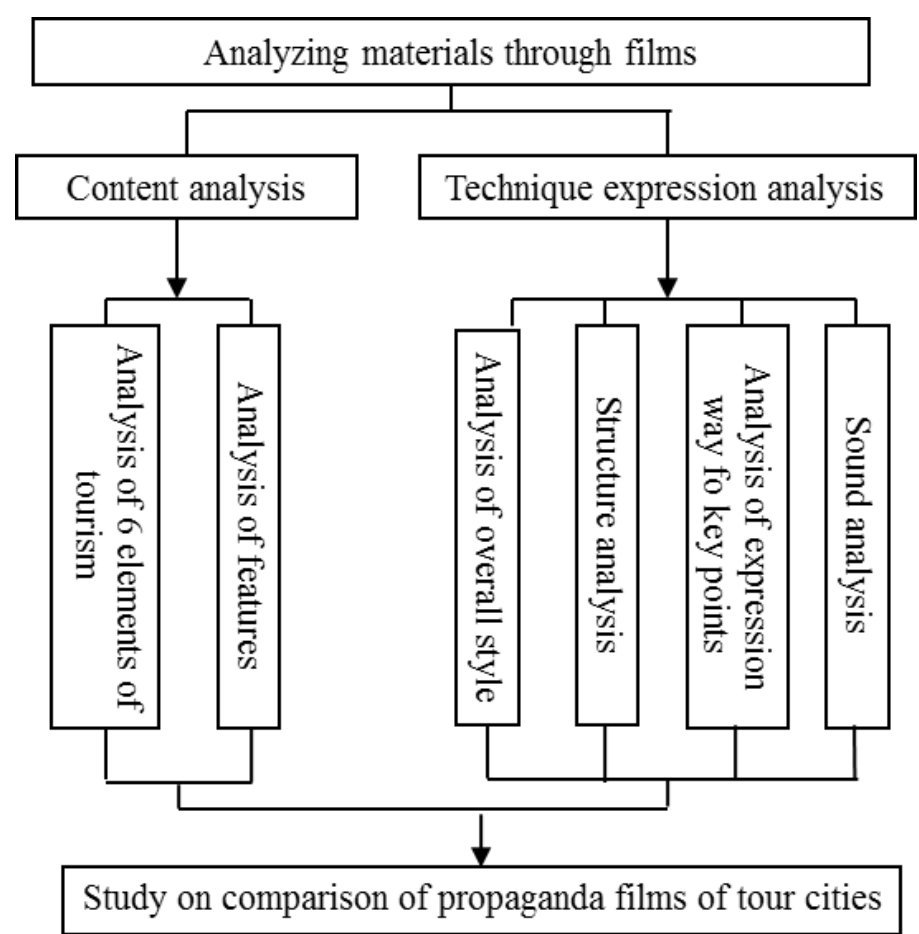

Figure 1. Research framework

\section{Data Research and Analysis Methods \\ Data collecting}

Internet, as the forth media besides television, broadcasting, magazines and periodicals, plays more and more important and indispensable tool for people's life, work and study. Moreover, the cyberspace is carrying big virtual capacity and rich resources. It is more convenient to download data through internet free from the limitation of paper files with longer file duration. Therefore, this article obtains research data through internet. http://u.cctv.com and www.chinacity.org.cn are chosen as fundamental websites on the basis of their authority and reference value. Considering the major rating, major tour cities as Beijing, Shanghai, Chongqing, Xi'an, Qingdao, Chengdu, Hangzhou, Nanjing and Xiamen are chosen as the study target of advertising videos.

\section{Method of data analysis}

CA is a study method upon advertising videos content, system and quantitative. Its nature is to analyze the information in the content and its variety which is the process to infer the exact meaning from meaningful sentences. The process of content analysis is reasoning.

According to the categories of visual elements, the indicators of content analysis can be divided into content indicators and form indicators. Content indicators mainly refer to the content of advertising videos content, mainly categorized according to the six key elements of tourism such as catering, housing, transportation, travel, shopping and entertainment. Form indications are the Performance practices of advertising videos. From the study into overall characteristics of advertising videos, there are elements such as overall style, structure, elements of performance and voice. The following quantitative analysis are going on according to the above mentioned standard. 
Table 1. Overall Style Comparison of the Tourism city image

\begin{tabular}{|c|c|c|}
\hline City & Overall Style & Characteristics of the style \\
\hline Beijing & \multirow{2}{*}{ Sightseeing films with the painting style } & Traditional \& exquisite \\
\hline Nanjing & & Soft \& ancient \\
\hline Chengdu & \multirow{2}{*}{ Feature films with TV style } & \\
\hline Chongqing & & Leisure \& cnarming \\
\hline Xi'an & \multirow{2}{*}{ Invitation for investment films in documentary style } & Ancient \& modern \\
\hline Qingdao & & European style \\
\hline Shanghai & \multirow{2}{*}{ Urban comprehensive film with co-occurrence style } & Fashionable \& soothing \\
\hline Shenzhen & & Cheerful \& rapid \\
\hline Xiamen & Advertising videos with argumentative style & Island flavor \\
\hline Hangzhou & Films of tour agency with painting style & River and lake flavor \\
\hline
\end{tabular}

\section{RESULTS}

\section{Deconstruction of Expression Techniques of Advertising Videos \\ Overall style of the tourism city image}

There are several styles to express the image of tourism city, including the painting style, the TV style, the co-occurrence style, the documentary style, and the argumentative writing style. The painting style pay attention to the pure appreciation, the graphic design, and strive to express the content of the film through the graphic and stylized static image. The TV style is with the feature of the TV drama through the dramatic plots. The documentary styles pursue the authenticity of life, pay attention to the real description of the details, usually use collage, clip to express. The co-occurrence style adopt the structure of multi thread, multi-level and multi angle, which has the characteristics of multi parts and big capacity. The style of augmentative writing is based on the typical structure of argumentation, provide the different arguments on the basis of the theme.

\section{Structure of advertising videos image}

The structure of the advertising videos can be analyzed from narrative/ non-narrative style, presentation perspective, internal logical relationship, time conversion of the content.

1) Narrative or non-narrative style. The films of Chongqing and Chengdu belong to the narrative one, the films of Shanghai and Shenzhen are comprehensive films with plots, while other films are nonnarrative films.

2) Presentation perspective. The presentation perspective mainly refers to the angles that story unfolds, such as from the perspectives of the tourists, the third person, the government, and so on. Almost all films are produced and filmed by government, of which $\mathrm{Xi}^{\prime}$ an and Chongqing are typically produced from the perspective of government. Yet there are more and more plots are shot from the perspective of tourists. For example, the film of Chongqing starts the story from a heroine back to her hometown and describes the image of Chongqing through what she sees and hears. The film of Chengdu uses the activities of tourists as its clue. The films of Shanghai and Shenzhen describe the interesting stories of foreign tourists in the course of sightseeing. In Shenzhen film, using foreign tourists' feeling as finishing touch, ending the story by engraving the theme slogan "Wonderful Shenzhen, Happy City" on the tourist's ceramic works; while some foreign tourists take photos of citizens' life in Shanghai film.

3) Internal logical relationship. In most films, the relationship between each element is mostly parallel, for example, from one second "sightseeing" cutting quickly transform to "entertainment" cutting, and return back to "sightseeing" cutting within 3 seconds. The kind of expression technology is some confusing. The films seldom embody the relationships of whole-to-part, sequence and comparison. For 
example, the film of Xiamen is the obvious whole-to-part structure with the argumentative style; it straightly puts forward the theme of "Warm Xiamen, Island Garden", and then raises different subarguments to bring to the theme, e.g. the convenient traffic. In the film of Shanghai, it shows the relationship of sequence by using the coherent shots to explain plots of marriage, giving birth, children growing and going to university.

4) Internal logical relationship. In most films, the relationship between each element is mostly parallel, for example, from one second "sightseeing" cutting quickly transform to "entertainment" cutting, and return back to "sightseeing" cutting within 3 seconds. The kind of expression technology is some confusing. The films seldom embody the relationships of whole-to-part, sequence and comparison. For example, the film of Xiamen is the obvious whole-to-part structure with the argumentative style; it straightly puts forward the theme of "Warm Xiamen, Island Garden", and then raises different subarguments to bring to the theme, e.g. the convenient traffic. In the film of Shanghai, it shows the relationship of sequence by using the coherent shots to explain plots of marriage, giving birth, children growing and going to university.

\section{Content Analysis of Six Tourism Elements}

There are six key elements in tour cities elements, including catering (special snacks), accommodation (star hotels), transportation (water transport, land transport, air transport), sightseeing (overall outlook of the city, scenic

Table 2. Comparative Analysis of the tourism elements in Advertising videos

\begin{tabular}{|c|c|}
\hline $\begin{array}{l}\text { Tourism } \\
\text { elements }\end{array}$ & Comparative analysis of content \\
\hline Catering & $\begin{array}{l}\text { Most advertising videos give introduction to special snacks. About } 30 \% \text { of the films only show the specialties } \\
\text { and scene of enjoying but not the production process. It shows the universality of specialty in the films. The } \\
\text { contents of tea are involved in } 50 \% \text { of the advertising videos. Films concerning cuisine are comparatively less } \\
\text { with a proportion of } 30 \% \text {. The contents of dining places are involved in about } 40 \% \text { of the films. }\end{array}$ \\
\hline Accommodation & $\begin{array}{l}\text { There are } 80 \% \text { of the films introducing star hotels. It indicates that star hotels are commonly accepted. } \\
\text { Budget hotels and residential homes are mentioned in the film of Xiamen. It shows that cities are paying } \\
\text { more attention to the diversified development of accommodation and enhance the advertising videos of } \\
\text { special accommodation service to meet requirements from different levels of customers. }\end{array}$ \\
\hline rtation & $\begin{array}{l}\text { There are four kinds of transportation in advertising videos, including water transportation (70\%), land } \\
\text { transportation ( } 80 \%) \text {, air transportation ( } 80 \%) \text { and others }(70 \%) \text {. The accessibility is very important for tourists. } \\
\text { In addition, Pedi cab in Beijing, motor bikes and bikes in Xi'an and Chongqing, cable car in Chengdu, painted } \\
\text { pleasure boats in Hangzhou, bicycles in Xiamen, as the special transportation ways not only advocate the } \\
\text { regional characteristics but also increase the interest of tour transportation. }\end{array}$ \\
\hline Sightseeing & $\begin{array}{l}\text { There are } 50 \% \text { of the films introducing historical scenic spots, } 70 \% \text { displaying overall outlook of the cities. } \\
\text { Shaping the overall image of the city is the most commonly used promotional techniques, objectively } \\
\text { reflecting the advocacy role of tourism on the city. Only } 10 \% \text { of the videos are not related to tourism and } \\
\text { recreational scenic spots, which reflects these themes has been widely respected and applied by the } \\
\text { photographer. Videos related to the museum are only } 20 \% \text {; only } 20 \% \text { of the videos mention recreation and } \\
\text { leisure resort, which reflects the current need trends of the domestic tourism market. The } 50 \% \text { of the } \\
\text { advertising videos describe special interest program, such as Beijing's Hutong Tour, Chongqing's Red Tour, } \\
\text { Sichuan Panda and Folk Tour, Xiamen's Island Tour and Strait Tour. }\end{array}$ \\
\hline Shopping & $\begin{array}{l}\text { The } 80 \% \text { of the films present souvenirs, indicating that souvenirs are widely recognized by tourists. There are } \\
\text { commercial districts }(30 \%) \text {, characteristic lanes and streets }(40 \%) \text {, shopping malls }(40 \%) \text { and non-department } \\
\text { store shopping places (30\%) in the films. It indicates that these different types of shopping areas are } \\
\text { complementary and mutually reinforcing. However, the intentions of photographers are not very obvious and } \\
\text { random. The shopping parts are not the necessary component of image promotion. }\end{array}$ \\
\hline Entertainment & $\begin{array}{l}\text { The elements of science and education are involved in } 60 \% \text { of the videos, especially in Beijing, Shanghai, } \\
\text { Chongqing, Xi'an, Qingdao and Xiamen, which are all famous cities for their advancement of high education } \\
\text { and renowned universities and scientific research institutions. All films focus on the introduction of culture. } \\
\text { That means culture is the core of tourism city images. The } 40 \% \text { of films introduce festivals and events, which } \\
\text { shows the interaction and transferring of cities' economy and tourism. }\end{array}$ \\
\hline
\end{tabular}


Table 3. Expression Comparison of the City Tourism image

\begin{tabular}{ccccccc}
\hline \multirow{2}{*}{ City } & \multicolumn{7}{c}{ Time proportion (\%) } \\
\cline { 2 - 7 } & Sightseeing & Accommodation & Shopping & Entertainment & Catering & Transportation \\
\hline Beijing & 57.55 & 2.83 & 2.83 & 31.13 & 2.83 & 2.83 \\
\hline Shanghai & 20.00 & 1.27 & 9.84 & 48.25 & 6.67 & 13.97 \\
\hline Chongqing & 22.03 & 3.45 & 21.84 & 7.66 & 6.32 & 38.70 \\
\hline Xi'an & 51.38 & 0 & 1.58 & 39.13 & 1.98 & 5.93 \\
\hline Qingdao & 46.53 & 2.26 & 6.46 & 27.30 & 4.68 & 12.76 \\
\hline Chengdu & 42.34 & 0.58 & 7.42 & 25.99 & 15.55 & 8.12 \\
\hline Hangzhou & 30.00 & 0 & 10.00 & 33.33 & 16.67 & 10.00 \\
\hline Nanjing & 64.86 & 0.71 & 3.54 & 17.69 & 1.89 & 11.32 \\
\hline Shenzhen & 25.81 & 4.51 & 5.01 & 54.39 & 3.26 & 7.02 \\
\hline Xiamen & 40.51 & 5.19 & 5.63 & 36.75 & 8.17 & 3.75 \\
\hline
\end{tabular}

spots), culture and entertainment, which are the main body of the advertising videos. Other parts besides six elements are the necessary complements for the advertising videos show the characteristics of the city. The cultural elements constitute $60 \%$ of the samples, the economic elements and humane elements are both $40 \%$, the environmental elements are $30 \%$, while the geographical elements are only $20 \%$. In addition, all advertising videos contain the relative themes. Except for Hangzhou and Nanjing, all the films includes the characteristic elements besides six key elements of tourism, which support the theme. For example, the introduction of location and island environment are to foil the theme of "Warm Xiamen, Island Garden".

Table 3 shows the time length, proportion of the tourism elements in advertising videos. Whether from the sequence or from the time length, "sightseeing" and "entertainment" are key points in the six elements and play the leading roles in unfolding stories and advocating themes. "Accommodation" has the most limit time or even is not involved in the film. "Shopping" and "transportation" are necessary part of the films and sometimes have obvious randomness.

\section{Voice in Advertising Videos}

The voice of the advertising videos is the important expression pattern. This is somewhat different from the usual product placement because it may involve promotion of an image. However, it does mean that by choice of the type of song that specific age groups could be targeted. A notable benefit may be that apart from the destination being featured in the lyrics, it may also be featured in an accompanying video clip. (Kay, 2006)Our results showed about half of the films have the voice-over. These films usually use the commentary (in donut or monologue) to implement the combination of sound and picture. Other films without voice-over combine the music with picture, which are synchronous and can change according to the rhythm of each other. Sometimes the voiceover also can be combined with music, which is to help heightening the atmosphere, adding images, and deepening the role of the theme. For example, the piano accompaniment of famous pianist from China-Lang Lang -in the film of Shanghai not only set off the solemn and elegant atmosphere, but also gives guidance for the paly speed for film with the music goes up and down.

\section{CONCLUSIONS}

\section{Content Orientation of the Films}

As for the content of the advertising videos, the photographers emphasize two aspects of the tourism six elements, i.e. Sightseeing and Entertainment, to highlight the city tourism image; while another three aspects, Catering, Shopping and Transportation, are the necessary supplements in the film. However, the information about last element "Accommodation" is seldom expressed or ever neglected in the film. In addition, the advertising 
videos tend to display the trend of development of tour city images by adding cultural, economic, humane, environmental and geographical elements.

\section{Performance Techniques Orientation of the Photographers}

As for the expression technique of the advertising videos, the styles are more and more various, for example, the painting, TV, co-occurrence, documentary and argumentation style in the samples. Most photographers build the framework of the films by using non-narrative structure to depict tour city images in a concise and simple way. The reason maybe most films are produced from the perspective of government. However, the diversity and infectivity of narrative structure is cannot be ignored, and show its advantage in some films. Based on the structure and perspective of the film, the interior logical relationship tends to be parallel, paratactic, with only few using structures of whole-to-part, sequence, comparison. As a result, the richness and logic of internal relationships should be strengthened so as to avoid the confusion or rigidness. The photographers usually acquire time transformation, especially day and night transformation, to express the change of scenery; while the space transformation is seldom used. As for the voice of the films, the voice-over and music are usually used in most films. The combination of sound and picture, and the wide application of multimedia become the new trend.

\section{SUGGESTION}

\section{Some Suggestions on Shooting Advertising Videos for Tour City Image}

(1) On shooting subject. To realize diversity of the subject. At present, most subjects are limited to government institutes such as Tourism Bureau, News Office, etc. More subjects such as citizens, tourists and press should be encouraged to take part in to shoot more creative and more appealing films.

(2) On content. The six tourism elements are unevenly distributed in the films. The proportion of "Sightseeing" and "Entertainment" is as much as 2/3; while there are little information on "Accommodation". The other three elements are with randomness. The local elements of culture, economy, human, environment and geography tend to become more important. Therefore, the six elements need to be re-organized under the premise of balanced distribution. It is allowed to add the proportions of the individual elements when the elements are typical or strongly recommended. Meanwhile, the more attention should be given to the information of "Accommodation". With the integration of tourism industry with other industries, the new tourism format should be considered and presented as the element in the film, for example, the high-speed railway tourism, the self-driving camp, the industrial tourism, and so on. Last but not least, the characteristic elements such as cultural element can be appropriately added into the film.

(3) On techniques of the photographers. The future films pursue the novel and creative idea to avoid the single story. Hence, the theme is unfold through the combination of non-narrative and narrative structure, the clear interial logical relationship, the combined transformation of space and time, the clever use of voice.

\section{Some Advice on Promoting Tour City Image}

On the basis of above mentioned example research, and referring to some other image advertising videos in the course of research, the following suggestions are put forward:

(1) Comprehensive and diversified contents. In addition to the traditional six elements of tourism, elements as cultural, economic, humane, environmental and geographical need to be taken into consideration so as to enhance the overall image of city tourism.

(2) Special results. The special result is usually made through special effects such as celebrity, branding and implied effects. The advertising videos of the famous land of rivers and lakes -Wuzhen is an example of star effect by inviting the famous Taiwan singer and film star -Liu Ruoying. 
(3) Diversification in forms. Some advertising videos adopt form of TV series to analyses image by chapters, such as the chapter of landscape, humanity, ect.

(4) Diversification in methods. Besides making use of advertising videos, it is also good choice to combine net advertisement, TV advertisement, publicity materials, newspaper and magazines and outdoor advertising signs.

(5) Emotional communication. It is the ultimate goal of image advertising videos to form the emotional consensus with tourists, adding emotion part to the process of advertising videos, through which the public can interact affectively with the city.

(6) Public-oriented. It is the direct intention of image advertising videos to the targeted market through adopting different methods and content to different people groups.

(7) Times. The obvious characteristics of times of images are to keep up with the time and constantly bring forth new ideas. Only by keeping the pace of times and practice can the advertising videos works remain invisible. The images of World Expo in Shanghai with the theme "City, Better Life", and Olympic Games in Beijing with the theme "Experience Beijing, Experience Olympic" are highly contemporary examples of image advertising videos.

From the process of analysis, we can see that the shooting subjects have obvious intention to advertising videos while shooting image films. No matter it is the diversity of content or the complex of performance techniques, the purpose is to achieve best image advertising videos of the tour city. Researches nowadays are mainly based on the method of movie reviews. Therefore, they are, to some extent, subjective. It order to get more objective, convincing data and conclusion, we need to study further. Audience and media analysis must be taken into consideration in the further study. Promotional media make improvements after combining audience perception and getting feedback from audience. Or draw conclusion and general strategies from massive films combining with other media forms. All these are valuable to academic research.

\section{ACKNOWLEDGEMENTS}

This research was financially supported by Ministry of Education of Humanities and Social Sciences Research Youth Fund Project "Study on the High-speed Rail Tourism Economic Belt in Spatial Economics Perspective" (Grant No. 13YJC790042)

\section{REFERENCES}

Baloglu, S., \& McCleary, K. W. (1999). A Model of Destination Image Formation. Annals of Tourism Research, 26(4), 808-889.

Campelo, A., Aitken, R., \& Gnoth, J. (2011). Visual Rhetoric and Ethics in Marketing of Destinations. Journal of Travel Research, 50(1), 3-14.

Cheng, J. L. (2011). A research of the mechanism of urban tourism image perception. Human Geography, 26(3), 142146.

Choia, S., Lehtoa, Y. X., \& Morrison, M. A. (2007). Destination Image Representation on the Web: Content Analysis of Macau Travel Related Websites. Tourism Management, 27, 118-129.

Chon, K. S. (1990). The role of destination image in tourism: A review and discussion. The tourist review, $45(2), 2-9$.

Cohen-Hattab, K., \& Kerber, J. (2004). Literature, Cultural Identity and the Limits of Authenticity: A Composite Approach. International Journal of Tourism Research, 6(2), 57-73.

Echtner, C. M., \& Ritchie, J. B. (1993). The Measurement of Destination Image: An Empirical Assessment. Journal of Travel Research, 31(4), 3-13.

Huang, D. L. (2002). Advertising strategy of urban tourism image. Journal of Hunan Business College, 9(1), 61-63.

Kay, A. (2006). Promoting Tourism through Popular Music. Tourism Culture E Communication, 6(3), 209-213.

Krippendorf, K. (1980). Content Analysis: an Introduction to Its Methodology. Thousand Oaks, California: Sage.

Li, L. L. (1999). Exploration into the Propaganda Strategy of Tourism Destination Image. Shenzhen University Journal, 4, 87-93. 
Li, X., \& Wei, G. (2006). Television media strategies for the communication of the cultural tourism images of Hakka in west Fujian. Journal of Southwest Agricultural University (Social Science Edition), 4(3), 181-184.

Mackay K. Barbe D., Winkle C. M. V., \& Halpenny E. (2017). Social media activity in a festival context: temporal and content analysis. International Journal of Contemporary Hospitality Management, 29(2), 669-689

Malloy, C. D., \& Fennell, A. D. (1998). Codes of Ethics and Tourism: An Exploratory Content Analysis. Tourism Management, 19(5), 453-461.

Meaney, S., \& Robb, J. (2006). Shooting Ireland: the American Tourism Market and Promotional Film. Irish Geography, 39(2), 129-142.

Mercille, J. (2005). Media Effects on Image-the Case of Tibet. Annals of Tourism Research, 32(4), 1039-1055.

Neuendorf, K. A. (2002). The Content Analysis Guidebook. Thousand Oaks, California: Sage.

Padgett, M., \& Hall, C. M. (2001). Case study 4.3: Tourism at the Polls. In Hall, C. M., Kearsley, G. W. (Ed.), Tourism in New Zealand: An Introduction. Sydney: Oxford University Press.

Pan, S. (2011). The Role of TV Commercial Visuals in Forming Memorable and Impressive Destination Images. Journal of Travel Research, 50(2), 171-185.

Pike, S. (2002). Destination image analysis - a review of 142 papers from 1973 to 2000. Tourism management, 23(5), 541-549.

Swain, M., Brent, M., \& Long, V. H. (1999). Annals and Tourism Evolving: Indexing 25 years of Publication. Annals of Tourism Research, 25, 991-1014.

Tao, Y. G., Zhao, H. Y., \& Li, Y. L. (2010). Evaluation of influencing factors of tourism image based on a structure ture equation model. Human Geography, 25(6), 125-130.

Wang, X. (2008). Strategy to promote urban tourism image. China Social Sciences Press: Beijing.

Yan, Q. Y., \& Zhang, H. Q. (2010). The Determinants of the 1999 and 2007 Chinese Golden Holiday System-A Content Analysis of Official Documentation. Tourism Management, 31(6), 881-890.

Zhou, K., \& Fang, Z. W. (2010). A study on the strategy of TV advertising communication in Korean tourism image. Global Vision, (5), 62-66.

\section{http://www.ejmste.com}

